\title{
Количественное определение содержания бора в стеклах с помощью волнодисперсионного рентгенофлуоресцентного спектрометра
}

УДК 543.427

\begin{abstract}
Приведены результаты количественного определения содержания оксида бора в стекле методом РФС на спектрометре ZSX Primus IV Rigaku с помощью рентгеновской трубки, мощностью 4 кВт, и современного синтетического многослойного кристалла-анализатора RX85. Проведена экспериментальная проверка системы автоматического контроля давления для поддержания стабильного вакуума в измерительной камере. Показано влияние этого параметра на стабильность полученных результатов. Тесты на повторяемость подтвердили качество полученных данных.
\end{abstract}

Ключевые слова: бор, синтетический многослойный кристалл-анализатор RX85, система автоматического контроля давления АРС, метод прессованных порошков, стекольный порошок

Статья получена 7.02.2021 Принята к публикации 24.02.2021

\section{Введение}

Оксид бора $\left(\mathrm{B}_{2} \mathrm{O}_{3}\right.$ - ангидрид борной кислоты) важный компонент, который используется при производстве стекла. Его добавляют для снижения температуры размягчения без изменения таких характеристик, как коэффициент теплового расширения или химическая стойкость.

Длина волны характеристического рентгеновского излучения бора, B-К $\alpha$, достаточно велика, что затрудняет анализ этого элемента методом рентгенофлуоресцентной спектрометрии (РФС). Цель работы состояла в создании благоприятных условий и проведении эксперимента по количественному определению содержания бора в стеклах с помощью рентгенофлуоресцентного спектрометра.

\section{Условия эксперимента и оборудование}

Измерения проводили на волнодисперсионном рентгенофлуоресцентном спектрометре ZSX Primus IV с рентгеновской трубкой, мощностью 4 кВт (30 кB и 120 мА), с ультратонким бериллиевым окном, толщиной 30 мкм и Rh-анодом, а также стандартным набором из четырех кристаллов-анализаторов, перекрывающих диапазон элементов от кислорода (8) до кюрия (96). Дополнительно в спектрометр был установлен синтетический многослойный кристалланализатор RX85, также использовалась высокочувствительная щель Соллера S8. Новый многослойный кристалл-анализатор RX85 имеет чувствительность, которая в 1,3 раза выше, чем у предыдущей модели $\mathrm{RX75.} \mathrm{Время} \mathrm{счета} \mathrm{составляло} 100$ с как для пика, так и для фона.

ZSX Primus IV идеально подходит для рутинного анализа порошковых проб. Расположение рентгеновской трубки и оптической системы сверху над пробой, регулируемая скорость вакуумирования, ловушка пыли и камера предварительного вакуумирования создают условия для безопасного анализа порошковых проб. Конструктивная особенность верхнего расположения трубки предусматривает защиту от попадания частиц порошковой пробы на рентгеновскую трубку и оптическую систему, а также предохранение от пыли вакуумных насосов и магнитных клапанов. 
Процесс измерения автоматизирован: рука-манипулятор забирает образец, переносит его в тамбур, где создан вакуум, затем проводится анализ. После его окончания рука возвращает пробу на место и берет следующую. В среднем, в зависимости от количества задействованных в работе кристаллов, процедура длится от 5 до 40 мин.

Для анализа бора использовали систему автоматического контроля давления (АРC), которая поддерживает постоянный уровень вакуума в пробной и оптической камерах в процессе измерения. Система АРС необходима, поскольку флуктуации вакуума на пути рентгеновского луча могут вызвать колебания интенсивности рентгеновского излучения B-К $\alpha$ из-за большой длины волны характеристической линии.

Для коррекции перекрытия линия Pb-L $\beta 1$ была измерена с помощью кристалла-анализатора $\operatorname{LiF}(200)$ и щели Соллера высокого разрешения S2.

Программное обеспечение спектрометра разработано для удобства работы, как при качественном, так и количественном анализе.

Последовательное меню (Flowbar) в окне количественного анализа облегчает пользователю создание градуировочных характеристик. Окна программы "Таблица идентификатора пробы" и "Работа программы" помогают выполнять ежедневные измерения.

\section{Стандарты и подготовка проб}

Для построения градуировочных характеристик использовали сертифицированные стандартные образцы NIST SRM92, SRM1411 и SRM1412 (стекла) совместно с диоксидом кремния высокой чистоты $(99,99 \%)$ в качестве чистого образца.

Образцы SRM1411 и SRM1412 размалывали в вибрационной мельнице с использованием гарнитуры из карбида вольфрама. Далее порошки эталонных материалов NIST и диоксида кремния высокой чистоты, предварительно высушенные при температуре $110^{\circ} \mathrm{C}$, прессовали в кольца из ПВХ (внутренний диаметр 32 мм) с усилием $150 \mathrm{kH}$.

\section{Результаты}

На рис. 1 представлен калибровочный график, полученный с помощью эталонных материалов NIST (стекла) и диоксида кремния высокой чистоты. Применена коррекция перекрытия спектральных линий по Pb-L $\beta 1$.

Точность калибровки составила 0,063 вес. \%, расчетный нижний предел обнаружения (LLD) - 0,056 вес. \% для оксида бора и 0,017 вес. \% для бора.

\section{(D) Rigalku}

\section{Leading With Innovation}

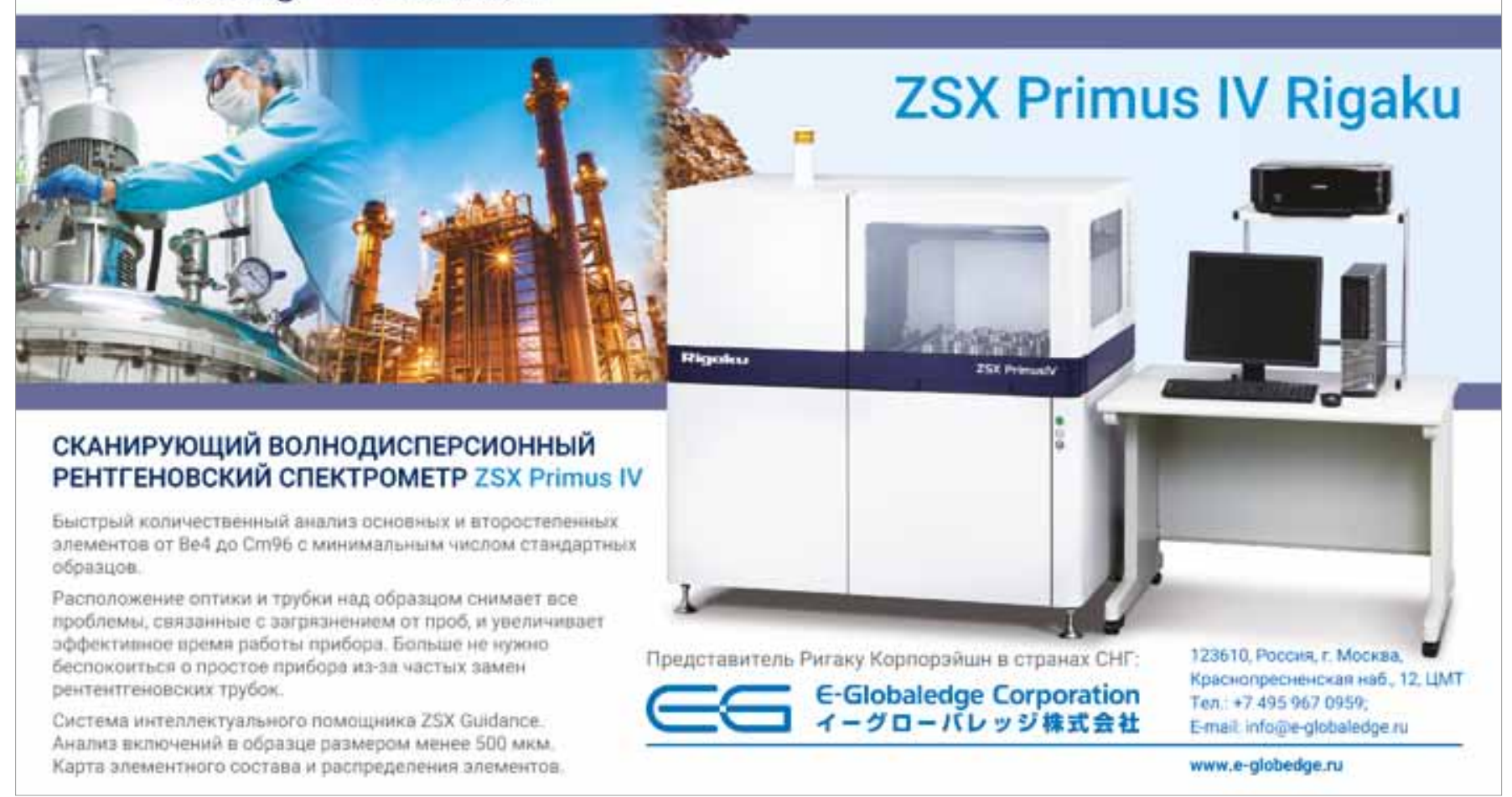




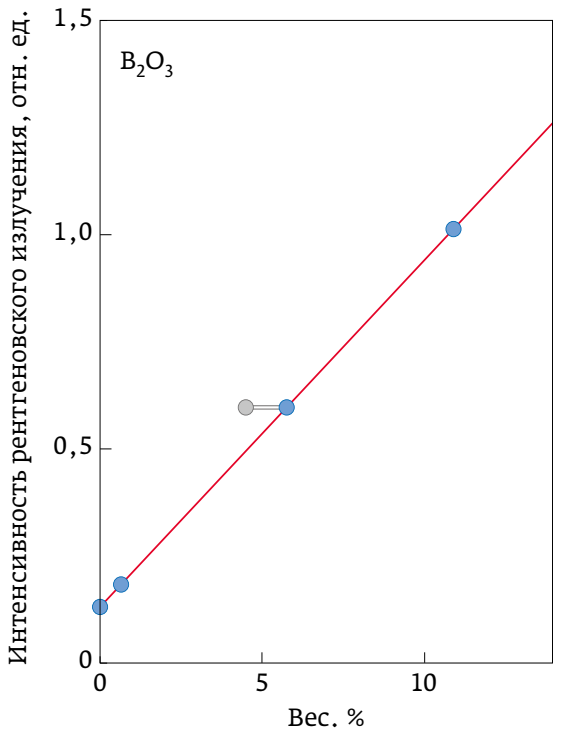

Puc. 1.

Калибровочный график

Точность калибровки рассчитывали по формуле:

$$
\text { Accuracy }=\sqrt{\frac{\sum_{i}\left(C_{i}-\hat{C}_{i}\right)^{2}}{n-2}},
$$

где: $C_{i}$ - расчетная концентрация стандартного образца;

$\hat{C}_{i}-$ паспортная концентрация стандартного образца;

n- число стандартных образцов.

Параметр LLD рассчитывали как трехкратное теоретическое стандартное отклонение измеренного образца.

Тесты на повторяемость (10 измерений), во время которых пробы оставались внутри спектрометра, проводили на образцах NIST SRM92 (аттестованное содержание $\mathrm{B}_{2} \mathrm{O}_{3}-0,70$ вес. \%) и SRM1411 (аттестованное содержание $\mathrm{B}_{2} \mathrm{O}_{3}-10,94$ вес. \%). Результаты измерений представлены в табл. 1.

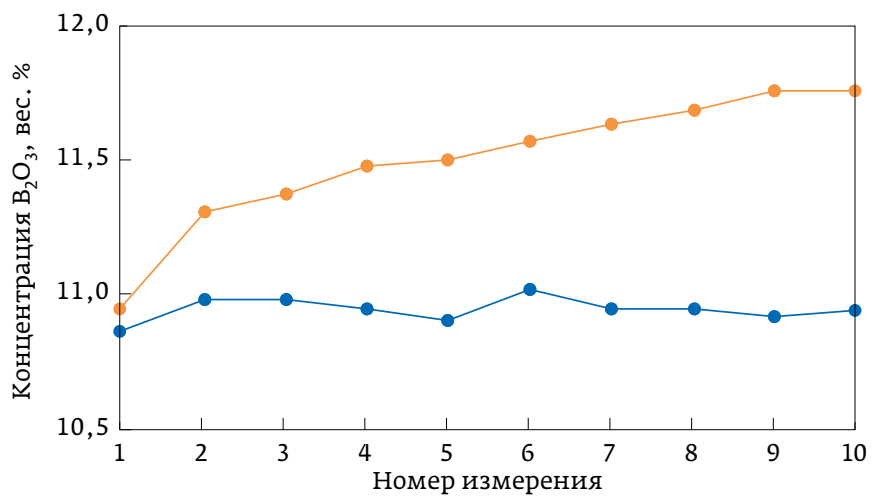

Puc. 2. Сравнение стабильности при включенной (синий) и выключенной (оранжевый) системе АРС
Таблица 1. Тест повторяемости результатов дия $\mathrm{B}_{2} \mathrm{O}_{3}$, вес. \%

\begin{tabular}{l|c|c}
\hline Проба & NIST SRM92 & NIST SRM1411 \\
\hline$n=1$ & 0,78 & 10,88 \\
\hline 2 & 0,74 & 10,98 \\
\hline 3 & 0,73 & 10,98 \\
\hline 4 & 0,76 & 10,95 \\
\hdashline 5 & 0,77 & 10,90 \\
\hline 6 & 0,76 & 11,02 \\
\hline 7 & 0,73 & 10,94 \\
\hdashline 8 & 0,74 & 10,94 \\
\hline 9 & 0,78 & 10,91 \\
\hline 10 & 0,79 & 10,94 \\
\hline Среднее & 0,76 & 10,94 \\
\hline Стандартное отклонение & $\mathbf{0 , 0 2 1}$ & $\mathbf{0 , 0 4 1}$ \\
\hline RSD & $\mathbf{2 , 7 8 \%}$ & $\mathbf{0 , 3 8 \%}$ \\
\hline
\end{tabular}

\section{Эффект функции АРС при анализе бора}

На рис. 2 показаны результаты двух тестов на повторяемость по десяти измерениям со включенной и выключенной системой АРС. Во время анализа при выключенной АРС давление в пробной и аналитической камерах изменяется, что приводит к колебаниям интенсивности рентгеновского излучения линии B-К $\alpha$.

Эксперименты показали, что использование АРС может обеспечить высокую точность при измерении спектральных линий элементов с очень большой длиной волны, таких как C-K $\alpha$, B-К $\alpha$ или Be-K $\alpha$.

\section{Выводы}

Таким образом, применение спектрометра ZSX Primus IV, оснащенного рентгеновской трубкой мощностью 4 кBт с Rh-мишенью и ультратонким бериллиевым окном, синтетическим многослойным кристаллом-анализатором RX85 позволяет проводить регулярное количественное определение содержания оксида бора в образцах стекла, подготовленных методом прессования.

Система автоматического контроля давления спектрометра ZSX Primus IV поддерживает постоянный уровень вакуума в пробной и аналитической камерах и должна применяться при измерении линий элементов с очень большой длиной волны, таких как $\mathrm{C}-\mathrm{K} \alpha, \mathrm{B}-\mathrm{K} \alpha$ или Ве-К $\alpha$.

Подготовия к.ф.-м.н. Н.Н. Герасименко по материалам: https://www.rigaku.com/applications 
XXII Международная научно-практическая конференция

студентов и молодых ученых

\section{«Химия и химическая технология в XXI веке»}

имени выдающихся химиков Л.П. Кулева и Н.М. Кижнера, посвященная 125-летию со дня основания Томского политехнического университета

$$
17 \text { - } 20 \text { мая 2021 г. }
$$

г. Томск, Томский политехнический университет

\section{Более 600 ученых из более чем 20 стран.}

\section{1 тематических секций:}

1. Химия и химическая технология неорганических веществ и материалов.

2. Химия и химическая технология органических веществ и материалов.

3. Теоретические и прикладные аспекты физической и аналитической химии.

3.1 подсекция «Теоретические и прикладные аспекты фармации и биотехнологии».

4. Технология и моделирование процессов подготовки и переработки углеводородного сырья.

5. Процессы и аппараты химической технологии.

6. Охрана окружающей среды и рациональное использование природных ресурсов.

7. Химия и химическая технология на иностранном языке (английский).

8. Химическая технология полимерных материалов.

9. Химия и химическая технология (для школьников).

10. Перспективные материалы и нанотехнологии.

В рамках конференции также пройдет симпозиум «Невалентные взаимодействия в кристаллохимическом дизайне и супрамолекулярная химия».

Научная программа конференции будет включать пленарные (30 минут), ключевые (20 минут), устные (10 минут) доклады и лекции ведущих ученых.

Рабочие языки конференции: русский и английский.

Присоединяйтесь к Online-трансляции пленарного заседания и секций конференции.

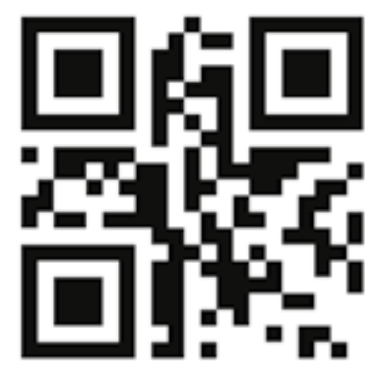

是

634050, Томск, пр. Ленина, 30

+7 (3822) 701-777 (1467)

@ orgcomHHт@tpu,ru

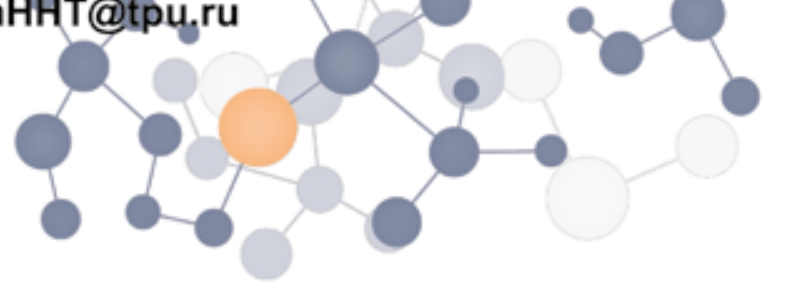

